\title{
Emergent technique in watercolor
}

\author{
Emily Garfield \\ SciArt Center, New York, USA \\ Correspondence to: Emily Garfield. SciArt Center, New York, USA. Email: emily@emilygarfield.com.
}

Submitted Mar 28, 2019. Accepted for publication Apr 10, 2019.

doi: $10.21037 /$ cdt.2019.04.04

View this article at: http://dx.doi.org/10.21037/cdt.2019.04.04

Maps grow through an emergent, "bottom-up" process similar to natural forms like cells and trees.

Likewise, I create my abstract map art emergently using rules inspired by my materials (Figure 1).

A single seed doesn't contain within it the entire plan for a tree; rather, the seed knows certain rules to follow, and a tree forms emergently—and fantastically consistently!from those rules.

Likewise, cities often grow originally through organic rules-people "self-organize" or naturally settle in places with resources and similar people, and communities grow likewise.

When I draw, I choose rules and constraints rather than end results; emergence rather than "top-down" predeterminism. I have a general hypothesis of how the rules will play out, but I don't plan the drawing out beforehand.

I particularly try to set up drawings with a certain amount of indeterminacy or "randomness", where my drawing self-organizes around a randomly-applied pattern. For example, I often start a drawing by dripping ink on the paper to simulate waterways, or by spraying acrylic wash and then forming it into streets (Figure 2).

The resulting drawings often end up looking like cells or maps (Figures 1-5).

The maps that I draw are therefore maps of their own creation, in that they're traces of where my hand has been over time. I generally think of them as time-based or performative, and often document my process with stopmotion animation to illustrate this (Figure 6).

Perhaps as I've been told, they might be "my brain drawing itself", as even brains are created emergently, and I'm curious to someday determine how much that is the case.

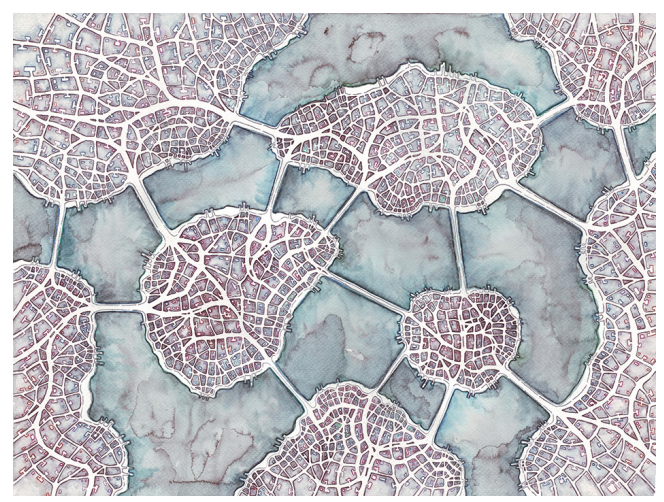

Figure 1 Aorta isles (Cityspace \#210)—water-soluble pencil on paper.

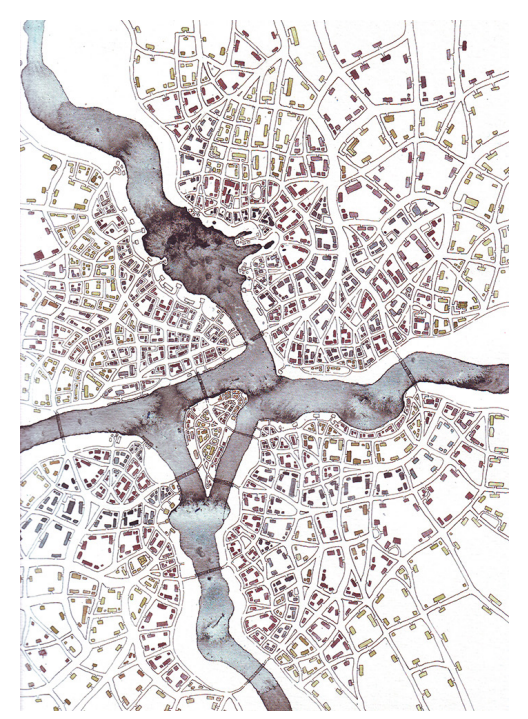

Figure 2 Infotrails (Cityspace 213)-ink, pen + watercolor on paper. 


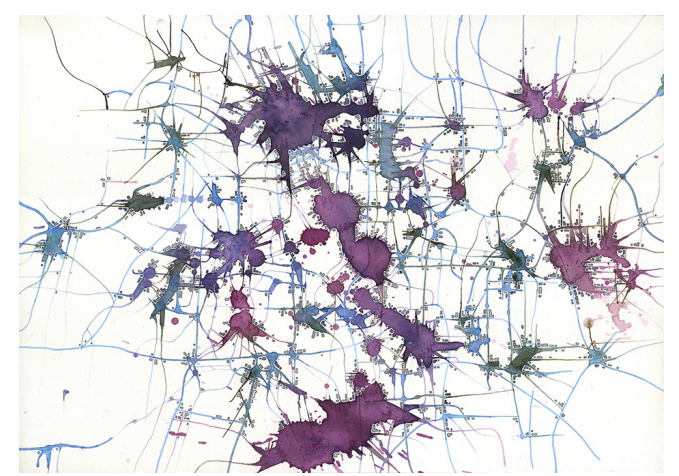

Figure 3 Organic algorithm \#16-acrylic, watercolor, pen + ink on paper.

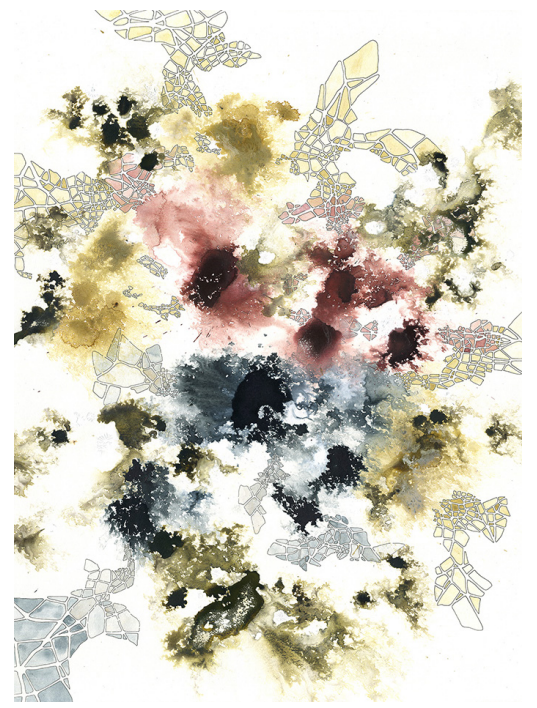

Figure 4 Organic algorithm \#41-ink + pen on paper.

\section{Author's statement}

Emily Garfield creates intricate maps of imaginary places that explore the origins of cities and the function of maps themselves. Her drawings are inspired by the visual language of maps and the fractal similarity that cities share with biological processes such as the patterns of cells and neurons. She has participated in exhibitions and taught workshops at venues including the Map Center at the Boston Public Library, the DeCordova Museum, the Peabody Essex Museum and the Snite Museum of Art at Notre Dame. She was the 2014 director of the Somerville Open Studios city-wide arts event, and now lives in New York where she helps to produce the Tribeca Art + Culture Night art festival. Emily Garfield received her BA in Visual Arts from Brown University, where she also studied the aesthetic response through cognitive science.

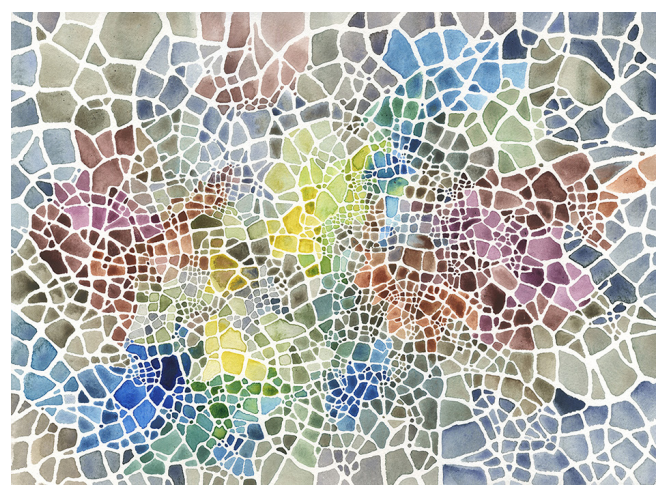

Figure 5 Bright spots (Cityspace 297)—watercolor on paper.

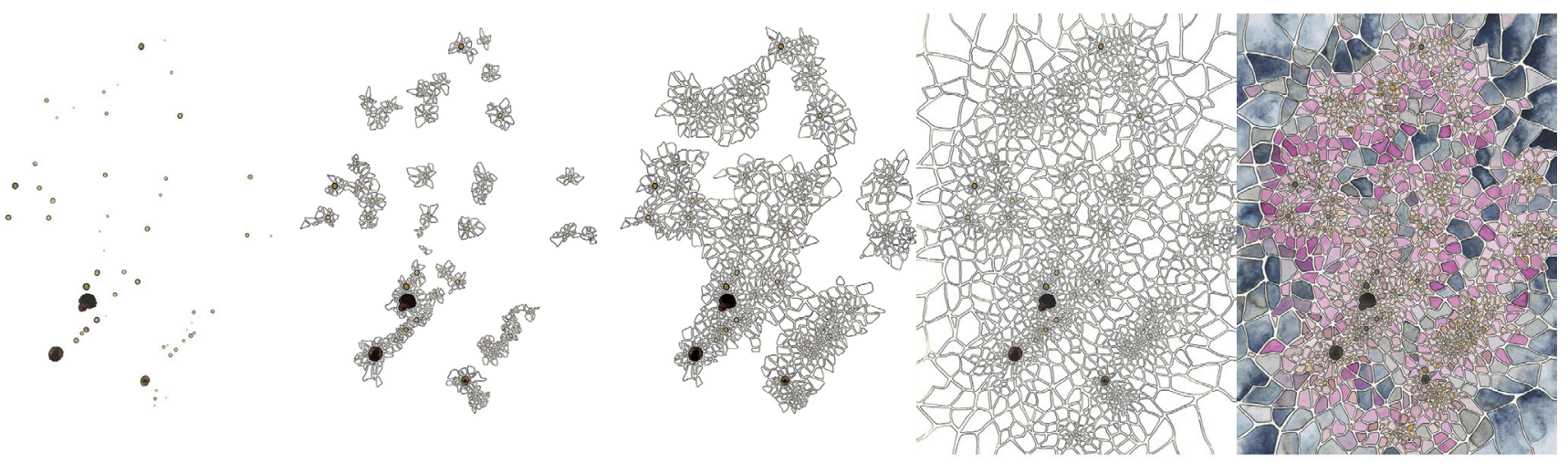

Figure 6 Organic algorithm \#11 (process)—ink, pen + watercolor on paper. 


\section{Acknowledgments}

None.

Cite this article as: Garfield E. Emergent technique in watercolor. Cardiovasc Diagn Ther 2020;10(1):101-103. doi: $10.21037 / \mathrm{cdt} .2019 .04 .04$

\section{Footnote}

Conflicts of Interest: The author has no conflicts of interest to declare. 